\title{
Incidence of and Risk factors for perioperative respiratory adverse events in children: a prospective cohort study BEN KHALIFA Sonia, ABBES Ahmed ${ }^{*}$
}

Department of Anesthesia and Intensive Care, Children's Hospital, Tunis, Tunisia University of Tunis El Manar, Faculty of Medicine of Tunis

\section{Background:}

Respiratory adverse events represent a major cause of perioperative morbidity in pediatric anesthesia. Few prospective published studies $(1,2)$ had identified risk factors for perioperative respiratory adverse events (PRAE) in children.

The aim of this study was to determine the incidence of and the risk factors for PRAE in children undergoing elective procedures under general anesthesia.

\section{Methods:}

Study design: prospective
observational study

DInclusion criteria: Children
undergoing general anesthesia for elective procedures from November 2014 to November 2016.

Data collection: Demographic data, medical history of asthma, allergy, second hand smoking, night-snoring and sleep apnea and recent upper respiratory tract infection.

Induction techniques and agents, airway management and the occurrence of PRAE (moment, management strategy and outcome) were recorded.

$\square$ Statistical analysis : Pearson's Chisquare and Fisher's exact tests were used. $\mathrm{P}<0.05$ was considered significant.

Multivariate Cox regression was employed to identify independent predictors for PRAE.

\section{References:}

1- Von Ungern-Sternberg BS and al. Risk assessment for respiratory complications in paediatric anaesthesia: a prospective cohort study. Lancet 2010;376:773-83.

2- Bordet $F$ and al. Risk factors for airway complications during general anaesthesia in paediatric patients.

Pediatric Anesthesia 2002;12:762-9.
Results :

$\square$ The study included 1022 children. DPRAE occurred in 96 (9.4\%) patients

$\square$ No patient was re-intubated, unremarkable outcome for all patients.

\section{Perioperative respiratory adverse events}

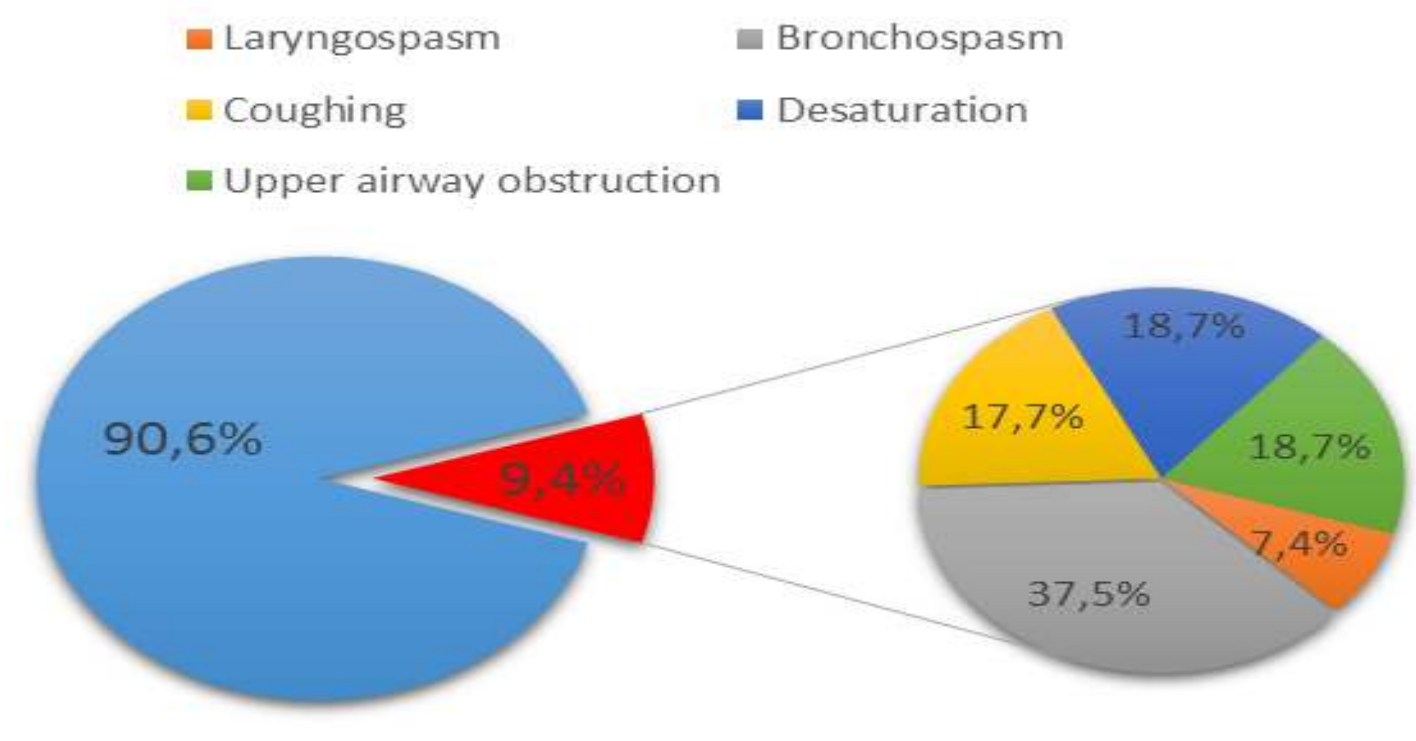

Figure 1: Incidence of PRAE

\begin{tabular}{|l|l|}
\hline Induction of anesthesia & $19.80 \%$ \\
\hline Maintenance & $16.70 \%$ \\
\hline Emergence & $63.50 \%$
\end{tabular}

Table 1: Moment of occurrence of PRAE

\begin{tabular}{llc}
\multicolumn{1}{c}{ Factors } & Odds-ratio / 95\% Cl & P \\
\hline Age $<12$ months & $2.41[1.29-4.50]$ & 0.005 \\
\hline $\begin{array}{l}\text { ASA class }>1 \\
\text { Recent Upper respiratory tract } \\
\text { infection }\end{array}$ & $2.89[1.01-8.27]$ & 0.047 \\
$\begin{array}{l}\text { Night-snoring } \\
\text { Use of LMA/FM }\end{array}$ & $2.22[1.36-3.61]$ & 0.001 \\
Endotracheal intubation/SGD & $1.78[1.00-3.17]$ & 0.047 \\
Peripheral regional nerve block & $2.44[1.18-5.05]$ & 0.016 \\
& $2.67[1.25-5.71]$ & 0.011 \\
\hline Inhalational induction & $0.51[0.30-0.88]$ & 0.015 \\
\hline
\end{tabular}

Table 2: Independent risk factors for PRAE

$\square$ Asthma and passive smoking were not associated with a higher risk of PRAE in our cohort.

\section{Conclusion:}

PRAE occurred more often on emergence. The main predictive factors for PRAE in our study were age under 1 year and history of recent upper airway tract infection. 